\title{
Increasing the Probability of Discovering Improved Antiepileptic Drugs through the Use of Human Epileptic Tissue
}

\author{
Jeffrey M Witkin ${ }^{1,2 *}$ and Jodi L Smith ${ }^{1^{*}}$ \\ ${ }^{1}$ Department of Neurological Surgery, Indiana University, School of Medicine, USA \\ ${ }^{2}$ Department of Chemistry \& Biochemistry, University of Wisconsin-Milwaukee, USA
}

*Correspondingauthor: Jeffrey M Witkin and Jodi L Smith, Departmentof Neurological

Surgery, Chemistry \& B iochemistry, USA, Email: jsmith@goodmancampbell.com

Received Date: November 02, 2018

Published Date: November 09, 2018

Keywords: Epilepsy; Antiepileptic drugs; Human brain; CERC-611; KRM-II-81

\section{Editorial}

Epilepsy affects millions of people world-wide with wideranging health and economic consequences [1]. A first-line approach to the control of epilepsy is through the administration of anticonvulsant drugs sometimes referred to as antiepileptics [2]. These medicines help control seizure activity but the evidence for controlling disease progression in patients is not firmly established [3]. There are many antiepileptics approved for clinical use [2] that dampen excitatory neurotransmission through different mechanisms including positive allosteric modulation of GABA (e.g., diazepam, valproic acid) and blockade of ion channels (e.g., gabapentin, lacosamide).

However, the need for improved antiepileptics is clearly mandated despite this plethora of antiepileptics. Standard of care agents do not fully control epilepsies and have a variety of sideeffect and safety issues including sedation, dizziness, cognitive impairment, and weight gain $[4,5]$. Patients typically take multiple antiepileptic drugs to increase the probability of seizure control and yet many patients continue to have seizures [6]. The continued occurrence of seizure activity not only puts the patient at risk, but each new seizure event increases the probability of subsequent epileptic events through sensitization mechanisms called seizure kindling [7,8]. Moreover, nerve cell death can arise [9]. Antiepilepticunresponsive seizures are life-disrupting and life-threatening [10]. One approach to seizure control to drug-refractory epilepsy is surgical resection of affected brain tissue and associated neural circuits as required to control seizures [11,12].
In addition to detecting novel biological substrates for the construction of improved antiepileptics [13], human epileptic tissue serves another key use in the discovery process. Human epileptic tissue data can significantly increase the ability to translate laboratory findings to the human epileptic patient. Combined with data from rodent models (e.g., seizure-provocation models), studies with human epileptic tissue offer direct assessment of the availability of the drug target in diseased tissue, the potential modification of the drug target by conventional antiepileptic drugs, and the functional ability of the new chemical entity to block seizures. Thus, patient-based biological data increase the probability that a newly discovered molecule will translate into antiepileptic efficacy in patients. Two examples are provided here to illustrate the value-added proposition of using human epileptic brain tissue in the drug discovery process.

Positive allosteric modulators of $\mathrm{GABA}_{\mathrm{A}}$ receptors are anticonvulsant (e.g., diazepam) and the $\alpha 1$ protein associated with $\mathrm{GABA}_{\mathrm{A}}$ receptors confers sedative liability [14]. A dedicated medicinal chemistry effort was directed toward increasing the oral bioavailitity of ethyl 8-ethynyl-6-(pyridin-2-yl)-4H-benzo[f] imidazo [1,5a] [1,4] diazepine-3-carboxylate (HZ-166) for the purpose of creating a more drug-like modulator of $\mathrm{GABA}_{\mathrm{A}}$ receptors with reduced interaction with $\alpha 1$ proteins associated with sedation. 5-(8-ethynyl-6-(pyridin-2-yl)-4H-benzo[f]imidazo[1,5] $[1,4]$ diazepin-3-yl) oxazole (KRM-II-81) was discovered through iterative chemistry steps where a bioisosteric replacement strategy 
was taken to reduce the metabolic liability of the ester function of HZ-166. The resulting oxazole, KRM-II-81, demonstrated selectivity for the $\alpha 3$ protein over $\alpha 1$ but with significant enhancements in its ability to expose plasma and brain through systemic and oral dosing [15]. It was postulated that KRM-II-81, that displayed anxiolytic activity $[15,16]$, would be anticonvulsant like diazepam but would have a larger separation in doses between those generating anticonvulsant vs. those producing motor-impairing effects. Multiple rodent seizure-provocation models confirmed this pharmacological profile [17]. However, additional confidence in whether this novel drug target of $\operatorname{GABA}_{A}(\alpha 2 / 3)$ receptors would be viable in patients was needed. Slices of cortical tissue resected from two epileptic patients were used to help establish this human translational data element. Electrophysiological recording of activated epileptic brain tissue demonstrated that KRM-II-81 significantly suppressed increased network activity induced by two distinct pharmacological agents (picrotoxin and AP-4) [15]. These human tissue data provided assurance that $\operatorname{GABA}_{A}(\alpha 2 / 3)$ receptors are present in epileptic brain and that KRM-II-81 is able to access these receptors in order to functionally dampen epileptic phenomenon. These conclusions regarding KRM-II-81 would not have been possible without the use of human epileptic brain tissue. Confidence in an investment in the clinical development of KRMII-81 is thus enhanced by these clinically-translatable findings.

A second example comes from the discovery of 6-[(1S)-1-[1[5-(2-hydroxyethoxy)-2-pyridyl] pyrazol -3-yl] ethyl]-3H-1,3benzothiazol-2-one (CERC-611, formerly known as LY3130481). CERC-611 is an AMPA receptor antagonist that selectively blocks AMPA receptors associated with the auxiliary protein TARP $\gamma-8$ [17]. Perampanel (Fycompa) blocks AMPA receptors globally across the brain to reduce fast excitatory neurotransmission [18] At the same time however, side-effects in animal models; [18-21] and in patients [22] of motor impairment are observed. These side effects limit the doses of perampanel that can be given and thereby potentially limit its efficacy as an antiepileptic agent. CERC-611was discovered through a multi-tiered compound library screening system [18] to find an AMPA receptor antagonist that had selectivity for AMPA receptors associated with TARP $\gamma-8$ over TARP $\gamma-2$. Screening was followed up by iterative medicinal chemistry campaigns for drug optimization [23]. The rationale for this search was based upon protein expression patterns; $\gamma-8$ is localized in forebrain regions in rodent and human brain, whereas $\gamma-2$ is located largely in cerebellum [24]. It was hypothesized that an AMPA receptor antagonist with selectivity for AMPA receptors associated with TARP $\gamma$-8 over $\gamma-2$ would retain the anticonvulsant efficacy of perampanel but would have a reduced liability for motor impact from minimized interaction with cerebellar AMPA receptors. This hypothesis was realized in rodent models $[18,25]$. However, despite activity of CERC-611 in multiple acute and chronic models of seizure provocation, it was still not clear if CERC-611 would function as an anticonvulsant with attenuated motor side-effect in patients with epilepsy. This possibility was evaluated with human epileptic tissue: CERC-611 selectively blocked AMPA current in human cortex but not cerebellum [18], whereas perampanel blocked in both tissue domains [18,21] mirroring its motoric disrupting pharmacology. Further, despite its actions upon only a subset of AMPA receptors, CERC-611 blocked network activity in slices freshly resected from human epileptic brain [25] as did perampanel [21]. As with KRMII-81, data from human epileptic brain was used to increase the basis for the proposition that CERC-611 would be antiepileptic in patients with decreased propensity for motoric problems. CERC611 is currently under clinical development.

Taken as a whole, combined experimental data input from the preclinical laboratory along with data derived from studies with human epileptic brain can help direct focus on novel drug targets for epilepsy and increase the prediction that pharmacological data from a new chemical entity will translate to efficacy in epileptic patients.

\section{Acknowledgment}

None

\section{Conflict of Interest}

No conflict of interest

\section{References}

1. Wijnen BFM, van Mastrigt GAPG, Evers SMAA, Gershuni O, Lambrechts DAJE, et al. (2017) A systematic review of economic evaluations of treatments for patients with epilepsy. Epilepsia 58(5): 706-726.

2. De Luca L, De Sarro G (2010) Anticonvulsants. In Burger's Medicinal Chemistry, Drug Discovery, and Development. DJ Abraham and DP Rotella, John Wiley \& Sons, Inc. ( $7^{\text {th }}$ edn).

3. Kaminski RM, Rogawski MA, Klitgaard H (2014) The potential of antiseizure drugs and agents that act on novel molecular targets as antiepileptogenic treatments. Neurotherapeutics 11(2): 385-400.

4. Perucca P, Gilliam FG (2012) Adverse effects of antiepileptic drugs. Lancet Neurol 11(9): 792-802.

5. Moavero R, Pisani LR, Pisani F, Curatolo P (2018) Safety and tolerability profile of new antiepileptic drug treatment in children with epilepsy. Expert Opin Drug Saf 17(10): 1015-1028.

6. Błaszczyk B, Miziak B, Czuczwar P, Wierzchowska-Cioch E, Pluta R, et al. (2018) A viewpoint on rational and irrational fixed-drug combinations. Expert Rev Clin Pharmacol 11(8): 761-771.

7. Teskey GC, Racine RJ (1993) Increased spontaneous unit discharge rates following electrical kindling in the rat. Brain Res 624(1-2): 11-18.

8. Avanzini G, Depaulis A, Tassinari A, de Curtis M (2013) Do seizures and epileptic activity worsen epilepsy and deteriorate cognitive function? Epilepsia 54 Suppl 8: 14-21.

9. Dingledine R, Varvel NH, Dudek FE (2014) When and how do seizures kill neurons, and is cell death relevant to epileptogenesis? Adv Exp Med Biol 813: 109-122.

10. Devinsky O, Hesdorffer DC, Thurman DJ, Lhatoo S, Richerson G (2016) Sudden unexpected death in epilepsy: epidemiology, mechanisms, and prevention. Lancet Neurol 15(10): 1075-1088.

11. Hobbs JP, Smith JL, Beggs JM (2010) Aberrant neuronal avalanches in cortical tissue removed from juvenile epilepsy patients. J Clin Neurophysiol 27(6): 380-386.

12.Boling WW (2018) Surgical Considerations of Intractable Mesial Temporal Lobe Epilepsy. Brain Sci 8(2) pii: E35. 
13.Zhou X, Ma LM, Xiong Y, Huang H, Yuan JX, et al. (2016) Upregulated P2X3 Receptor Expression in Patients with Intractable Temporal Lobe Epilepsy and in a Rat Model of Epilepsy. Neurochem Res 41(6): 12631273.

14. McKernan RM, Rosahl TW, Reynolds DS, Sur C, Wafford KA, et al. (2000) Sedative but not anxiolytic properties of benzodiazepines are mediated by the GABA(A) receptor alpha1 subtype. Nat Neurosci 3(6): 587-592.

15. Poe MM, Methuku KR, Li G, Verma AR, Teske KA, Stafford DC, Arnold LA, Cramer JW, Jones TM, Cerne R, Krambis MJ, Witkin JM, Jambrina E, Rehman S, Ernst M, Cook JM, Schkeryantz JM (2016) Synthesis and Characterization of a Novel $\gamma$-Aminobutyric Acid Type A (GABAA) Receptor Ligand That Combines Outstanding Metabolic Stability, Pharmacokinetics, and Anxiolytic Efficacy. J Med Chem 59(23):1080010806.

16. Witkin JM, Cerne R, Wakulchik M, S J, Gleason SD, et al. (2017a) Further evaluation of the potential anxiolytic activity of imidazo[1,5-a][1,4] diazepin agents selective for $\alpha 2 / 3$-containing GABAA receptors. Pharmacol Biochem Behav 157: 35-40.

17. Witkin JM, Smith JL, Ping X, Gleason SD, Poe MM, et al. (2018) Bioisosteres of ethyl 8-ethynyl-6-(pyridin-2-yl)-4H-benzo[f]imidazo [1,5-a] $[1,4]$ diazepine-3-carboxylate (HZ-166) as novel alpha 2,3 selective potentiators of GABAA receptors: Improved bioavailability enhances anticonvulsant efficacy. Neuropharmacology 137: 332-343.

18. Kato AS, Burris KD, Gardinier KM, Gernert DL, Porter WJ, et al. (2016) Forebrain-selective AMPA-receptor antagonism guided by TARP $\gamma-8$ as an antiepileptic mechanism. Nat Med 22(12): 1496-1501.
19. Rogawski MA and Hanada T (2013) Preclinical pharmacology of perampanel, a selective non-competitive AMPA receptor antagonist. Acta Neurol Scand Suppl 127(suppl 197): 19-24.

20.Hanada T, Hashizume Y, Tokuhara N, Takenaka O, Kohmura N, et al. (2011) Perampanel: A novel, orally active, noncompetitive AMPAreceptor antagonist that reduces seizure activity in rodent models of epilepsy. Epilepsia 52: 1331-1340.

21.Zwart R, Sher E, Ping X, Jin X, Sims JR Jr, et al. (2014) Perampanel, an antagonist of $\alpha$-amino-3-hydroxy-5-methyl-4-isoxazolepropionic acid receptors, for the treatment of epilepsy: studies in human epileptic brain and nonepileptic brain and in rodent models. J Pharmacol Exp Ther 351(1): 124-133.

22. Youn SE, Kim SH, Ko A, Lee SH, Lee YM, et al. (2018) Adverse Events During Perampanel Adjunctive Therapy in Intractable Epilepsy. J Clin Neurol 14(3): 296-302.

23.Gardinier KM, Gernert DL, Porter WJ, Reel JK, Ornstein PL, et al. (2016) Discovery of the First $\alpha$-Amino-3-hydroxy-5-methyl-4isoxazolepropionic Acid (AMPA) Receptor Antagonist Dependent upon Transmembrane AMPA Receptor Regulatory Protein (TARP) $\gamma$-8. J Med Chem 59(10): 4753-4768.

24.Tomita S, Chen L, Kawasaki Y, Petralia RS, Wenthold RJ, et al. (2003) Functional studies and distribution define a family of transmembrane AMPA receptor regulatory proteins. J Cell Biol 161(4): 805-816.

25.Witkin JM, Schober DA, Gleason SD, Catlow JT, Porter WJ, et al. (2017b) Targeted Blockade of TARP- $\gamma 8$-Associated AMPA Receptors: Anticonvulsant Activity with the Selective Antagonist LY3130481 (CERC611). CNS Neurol Disord Drug Targets 16(10): 1099-1110. 